\title{
Exanthema subitum, Lake Tahoe Disease und Herpesvirus Typ 6 (HHV-6)-Infektion
}

\author{
Carl Mietens \\ Universitätskinderklinik Bochum, St. Josef-Hospital
}

Nachdem 1983 die Ätiologie der Ringelröteln durch Parvo-Virus B 19 durch Summers und Mitarb. und Clewly festgestellt werden konnte, scheint es, daß nunmehr der Erreger einer weiteren klassischen Kinderkrankheit, des Exanthema subitum (3-Tage-Fieber) identifiziert werden konnte.

Das Exanthema subitum ist eine relativ häufige Erkrankung bei Kindern unter 3 Jahren. Es wird geschätzt, daß etwa $30 \%$ aller Kinder mit den typischen Symptomen erkranken. Ohne längere Prodromi kommt es zu einem akuten Fieberanstieg, der meistens Temperaturen zwischen 39 und $40^{\circ} \mathrm{C}$ erreicht. Häufig ist ein Fieberkrampf mit dem initialen Temperaturanstieg assoziiert, der sich im allgemeinen durch eine gute Prognose auszeichnet. Seltener als bei Krämpfen im Rahmen anderer Virusinfekte kommt es zu Rezidiven. Die hohen Temperaturen bleiben meist 3 Tage bestehen und sind durch Antipyretika nur schwer beeinflußbar. Kurzzeitige Fiebersenkungen, die durch Parazetamol oder Aspirin bewirkt werden können, haben meist innerhalb weniger Stunden einen erneuten Fieberanstieg auf Temperatur über $39^{\circ} \mathrm{C}$ zur Folge. Am 3.-4. Tag tritt gleichzeitig mit der spontanen Entfieberung ein generalisiertes, kleinfleckiges Exanthem am ganzen Körper auf. Das kleinmakulöse Exanthem befällt Stamm und Extremitäten, weniger intensiv das Gesicht und verschwindet nach 1-2 Tagen. Die Leukopenie, das Versagen von antibiotischer Behandlung, der fehlende Nachweis von Bakterien und die hämatogene Übertragung, die 1950/51 nachgewiesen wurde, ließen schon lange an eine Virusätiologie denken, besonders da auch eine längere Inkubationszeit besteht.

1988 veröffentlichten Yamanishi und Mitarb. (1) einen Bericht über die Isolierung humaner Herpesviren Typ 6 (HHV-6) von Kindern mit Exanthema subitum. Es gelang ihnen, aus Lymphozyten des peripheren Blutes im akuten Stadium des 3-Tage-Fiebers humanes Herpesvirus-6 (HHV-6) zu isolieren und in den folgenden Tagen Antikörper gegen dieses Virus im Serum nachzuweisen. Im April dieses Jahres erschien eine weitere sehr sorgfältige Studie von Asano und Mitarb. (2), die HHV-6 aus Monozyten von Kindern mit Exanthema subitum isolierten. Der besondere Wert dieser Studie liegt darin, daß bis zum dritten Tag der klinischen Erscheinungen bei allen untersuchten Kindern mit Dreitagefieber HHV-6 isoliert werden konnte.
Danach nahm die Häufigkeit der Isolierungen ab, nach dem 7. Krankheitstag war kein Virus mehr nachweisbar. Auch aus dem Plasma der Patienten konnte HHV-6 - wenn auch weitaus seltener - isoliert werden. Morphologische Veränderungen der zum Nachweis verwendeten Gewebekulturzellen wurden zwischen dem 5. und dem 15. Tag nach Beginn der Kokultivierung von Nabelschnurblutzellen mit den Monozyten der Patienten nachgewiesen. Infizierte Zellen sind größer, pleomorphisch und haben ein ballonartiges Aussehen. Sie erinnern an Riesenzellen bzw. sog. „Eulenaugen-Zellen“.

Die Häufigkeit der Isolierungsrate aus dem Plasma betrug am 1. Tag $67 \%$ und reduzierte sich auf $13 \%$ am 4. Erkrankungstag. Am 4. Tag hatte nur noch ein einziger Probant das Virus im Serum.

Umgekehrt verhielt sich die Bildung neutralisierender Antikörper, die zum ersten Mal am Tag 3 nach der Erkrankung auftrat und vom 5. Tag an bei allen untersuchten Kindern mit Exanthema subitum im Serum vorhanden waren. Zum Nachweis der neutralisierenden Antikörper verwendeten die Autoren dieser Studie einen der 39 isolierten Virusstämme, der als FG1 Fujita GakuenStamm bezeichnet wurde in einem Testsystem, das Nabelschnurblutzellen enthielt.

Der Nachweis von HHV-6 in abnehmender Frequenz und der charakteristische Antikörperanstieg läßt einen ätiologischen Zusammenhang zwischen dieser Infektion und dem klinischen Bild des 3-Tage-Fiebers als sehr wahrscheinlich erscheinen. Das Virus, das ursprünglich von Patienten mit AIDS und anderen hämatologischen Erkrankungen isoliert wurde (3), dürfte demnach ein DNSVirus mit einem Durchmesser von 160 bis $200 \mathrm{~nm}$ sein. Inzwischen wurde in einer weiteren Studie von Suga und Mitarb. nachgewiesen, daß auch in Kontaktpersonen, die kein Exanthem zeigten, sondern nur an hochfieberhaften Infekten erkrankten, HHN-6 und steigende AK-Titer nachgewiesen werden konnten. Dies steht im Einklang mit Beobachtungen aus der Klinik, daß oftmals Kontaktkinder mit hochfieberhaften Infekten ohne Exanthem erkrankten. Winndorfer hat einmal von dem Exanthema subitum ohne Exanthem gesprochen. Von vielen anderen Viruserkrankungen ist bekannt, daß sie einen klinisch sehr unterschiedlichen Verlauf nehmen können, so daß auch eine Infektion ohne den Ausbruch eines Exanthems durchaus plausibel erscheint.

Asano und Mitarb. haben über zwei Kinder, einen 7 Monate alten Jungen und ein 5 Monate altes Mädchen berichtet, bei denen akut ohne Fieber ein maku- 
lo-papulöses Exanthem auftrat, das an leichte Masern erinnerte, jedoch am Stamm begann, am 2. Tag auf Hals und Gesicht überging und bald spontan abblaßte. Bei beiden Patienten wurde HHV-6 in Monocyten nachgewiesen und mittels Immunfluoreszenz HHV-6-Antikörper mit signifikantem Titeranstieg im Serum.

Durch Untersuchungen mit einem indirekten Fluoreszenztest gegen HHV-6 (FG 1 Stamm) wiesen Yoshikawa und Mitarb. nach, daß Antikörper gegen HHV-6 via Plazenta und Nabelschnur auf Neugeborene übertragen werden. $87 \%$ aller Neugeborenen in Japan hatten Antikörper gegen dieses Virus.

In den ersten 6 Lebensmonaten sank der Anteil durch Abbau des Nestschutzes auf 6\% und stieg dann bis zum Ende des 1 . Lebensjahres wieder auf $86 \%$ an. Die natürliche Durchseuchung erfolgt somit vorwiegend im 2. Lebenshalbjahr, daher der volkstümliche Ausdruck für das Exanthema subitum „Säuglings-Masern“.

Möglicherweise handelt es sich bei einer Reihe unklarer akuter Exantheme im Säuglingsalter ebenfalls um atypische Verlaufsformen des Exanthema subitum.

In diesem Zusammenhang muß das, LakeTahoe-Virus" erwähnt werden, das bei dem Ausbruch einer ,mysteriösen Erkrankung، in der Nähe des Lake Tahoe, einem Erholungsgebiet im US-Staat Nevada zuerst isoliert wurde. Die klinischen Erscheinungen, die auch als ,chronisches Müdigkeitssyndrom' bezeichnet werden, erinnern an eine persistierende infektiöse Mononukleose mit Lymphknotenschwellung, hochgradiger Abgeschlagenheit und neuropsychiatrischen Erscheinungen. Der Verlauf kann sich über Wochen und Monate bis zu einem Jahr hin erstrecken.

Auch hierbei wurde ein Virus der Herpesgruppe, bei dem es sich aber nicht um Herpes simplex-Virus, Epstein-Barr-Virus oder Cytomegalie-Virus handelt, und das ebenfalls als Humanes Herpes Virus Typ 6 bezeichnet wurde, isoliert $(5,6,7)$. Antikörper gegen dieses Virus werden bei AIDS-Patienten, bei malignen Lymphomen, bei lymphatischen Leukämien, Sarkoidose und bei anderen hämatologischen oder immunologischen Erkrankungen festgestellt. Während hier die Möglichkeit einer Sekundärinfektion bei gestörter Abwehrlage durchaus möglich ist, scheint es sich bei der Lake-Tahoe-Krankheit um ein eigenständiges Krankheitsbild zu handeln, das inzwischen auch in der Bundesrepublik, England und Uganda beobachtet wurde $(8,9,10,11,12)$.

Diese Untersuchungen werfen neue interessante Fragen auf: Sind der Erreger der, Lake-Tahoe-Erkrankung" und der Erreger des Exanthema subitum, die vorerst beide als HHV-6 bezeichnet werden, tatsächlich identisch oder handelt es sich um nahe verwandte Viren der Herpes-Gruppe? Ist das ,chronische Müdigkeitssyndrom ' die Manifestation einer Primärinfektion mit HHV-6 im Erwachsenenalter und das Exanthema subitum einer sol- chen im frühen Kindesalter oder spielt eine Reinfektion bei veränderter Immunitätslage eine Rolle? Schließlich kommt auch noch eine endogene Reaktivierung analog der ZosterErkrankung nach früher vorausgegangenen Varizellen in Frage, wogegen aber die Begrenzung der Erkrankungen auf die Lake-Tahoe-Region spricht.

Ungeklärt ist noch die Frage, ob das HHV-6 den einzigen Erreger des 3-Tage-Fiebers darstellt oder ob auch andere, möglicherweise verwandte Viren, ein ähnliches Krankheitsbild hervorrufen können.

Weitere Untersuchungen sind erforderlich und die oben genannten Befunde bedürfen noch der Bestätigung durch andere Forschergruppen, um als gesichert zu gelten. Die dargelegten Ergebnisse zeigen aber die eindrucksvolle Entwicklung der modernen Virusforschung und dokumentieren die Akribie, Ausdauer und den Fleiß der japanischen Untersucher.

\section{Literatur}

I Yamanishi, K., T. Okuno, K. Shiraki et al.: Identification of Human Herpesvirus-6 as a causal agent for Exanthem subitum I ancet 1988; $1: 1065-1067$

Asano, Y., T. Yoshikawa, S. Suga et al.: Viremia and neutralizing antibody response in infants with Exanthem subitum. The Journal of Pediatr. 1989; vol 114:535-539

'Salahuddin, S. Z., D. V. Ablashi, P. D. Markham et al.: Isolation of a new virus, HBLV, in patients with lymphoproliterative disorders Science 1986; 234:596-601

Suga, S., T. Yoshikawa, Y. Asano et al.: Human Herpesvirus-6 Inlection (Exanthem subitum) without Rash Pediatrics 1989; vol 83, 6: $1003-1006$

"Behan. P. O., W. M. H. Behan, E. J. Bell: The postviral Fatigue-Syndrome - An Analysis of the Findings in 50 Cases J. Infect. Dis. 1985; $10: 211-222$

- Jamal, G. A., S. Hansen: Electrophysiological studies in the postviral Fatigue-Syndrome J. Neurol. Neurosurg. Psychiatry 1985; 48: 691-694 Josephs, S. S. Z., D. V. Salahuddin, F. Ablashi et al.: (ienomic Analysis of the Human B-Lymphotropic Virus (HBL.V) Science 1986; 234: 601-603

"Krueger, G. R, F, B. Koch, D. V. Ablashi: Persistent Fatigue and Depression in a Patient with Antibody to Human B- Lymphotropic Virus. Lancet 1987; II: 36

"Tedder, R. S., M. Briggs, C. H. Cameron, R. Honess et al.: A Novel Lymphotropic Herpesvirus. Lancet 1987; II: 390-392

"Dow'ning, R. G., N. Sewankambo, D. Serwadda, R. Honess et al.: Isolation of Human Lymphotropic Herpesvirus from Uganda laneet 1987; I1: 390

11 Krueger, G. R. F., D. V. Ablashi: Human B-Lymphotropic Virus in Germany Lancel 1987; II: 694

12 Krueger, G. R. F.: Das ,Lake-Tahoc-Virus* Dt. Ärztcbl. 1988; 85: $1459-1466$

"Asano, Y., S. Suga, T. Yoshikawa, A. Urisu, T. Yazaki: Human herpesvirus type 6 infection (exanthema subitum) wothout fever I. Pediatr. $1989,115: 264-265$

i4 Yoshikawa, T., S. Suga, Y. Asano, T. Yazaki, H. Kodama, T. Ozaki: Distribution of antibodies to a causative agent of exanthem subitum (Human Herpesvirus-6) in healthy individuals. Pediatrics 1989 , 84: $675-677$

\section{Prof. Dr. med. C. Mieten}

Universitätskinderklinik - St. Josef-Hospital

Alexandrinenstr. 5

4630 Bochum 1 